\title{
RESEARCH OF RISK ASSESSMENT PROBLEM OF CONVERGENCE TRAJECTORIES OF THE TWO DYNAMIC OBJECTS
}

\author{
Alexander Goloskokov \\ Department of Software Engineering and Management Information Technologies \\ National Technical University "Kharkiv Polytechnic Institute» \\ 2 Kirpicheva str., Kharkiv, Ukraine, 61002 \\ goloskokov@ukr.net \\ Mykhailo Brodskyi \\ Software R\&D Services Company \\ GlobalLogic \\ 3B Novgorodskaya str., Kharkiv, Ukraine, 61000 \\ michael.brodskiy@gmail.com
}

\begin{abstract}
The statement of the risk assessment problem of convergence trajectories of dynamic objects is formulated. An example of the solution assessment problem of the convergence trajectories of two dynamic objects is considered. Modeling of aircraft traffic taking into account the influence of random perturbations in MatLab is carried out. Relative projections of the trajectories of two aircrafts are constructed. An assessment of the occurrence of a conflict situation between two dynamic objects is obtained, the results of this problem are analyzed.

The aim of research is developing an approach to risk assessment problem of convergence trajectories of dynamic objects.

The problem is solved in the test case with the given initial conditions.

Further development of the article consists in finding the probability of a conflict situation from the multidimensional Fokker-Planck-Kolmogorov equation.

The process of aircraft traffic is described by the random Markov process of Ornstein-Uhlenbeck.

Keywords: conflict situation, forecasting, aircraft, conflict situation assessment, conflict probability, dynamic object, stochastic differential equation.

\section{Introduction}

The problem of flight safety is actively discussing in the aviation community. This is due to the transition from centralized air traffic control (ATC) to decentralized. Solving the problem is possible with the introduction of the regime of "Free Flight" [1].

The concept of free flight assumes the existence of an environment in which the pilot is empowered to choose a route in real time without control by the controller. Therefore, the pilot himself is already responsible for safety and optimal flight performance [2].

A new concept that improves air traffic productivity and safety by optimizing the interaction of dispatchers, aircraft crews and other services through the integration of a digital data transmission system, improvement of the observation and automation techniques has been called cooperative ATC.

Due to the presence of a sufficiently large number of factors leading to the deviation of the aircraft from the specified parameters of the trajectory of motion, situations are possible where the norms of the safe distance between aircraft are violated. At the same time, there is a threat of collision, even if the initially planned flights are conflict-free and there is a system that controls air traffic. In conditions of rapidly changing air situation associated with the change in direction and the dynamics of the relative motion of aircraft, as well as with the reduction of separation standards, the role of the system for detecting and preventing dangerous approach of airplanes increases significantly.

The problem of detection and resolution of conflicts in the air is one of the most widely studied problems of air traffic control [3]. At present, work is underway to resolve conflicts in the air, but with the use of other methods and approaches [4].
\end{abstract}


In this situation, modeling the motion of aircraft under the influence of random external influences and assessing the likelihood of their dangerous convergence is an actual problem. Information systems based on stochastic differential equations that allow to predict conflict situations have not yet been implemented.

In [5], the problem of forecasting conflict situations is considered, and a model of aircraft traffic is constructed, taking into account the influence of random perturbations. This article is a continuation of [3], in which a study of the solution of the problem of assessing the conflict situation is carried out.

The International Civil Aviation Organization (ICAO) is developing and implementing a flight safety system one by one, but the effectiveness of these systems is questionable, since the problem of aircraft collision has not yet been resolved.

Conflict situations in the air and on the runways are continuing, the problem remains urgent now. Let's give several facts as an example [6-10]:

- October 23, 2008 - two planes with six passengers collided over Colorado;

- December 18, 2008 - two small aircrafts collided over the suburbs of Sydney;

- January 20, 2009 - a collision of two Mirage F1 fighters over Spain;

- February 11, 2009 - two light-engine aircraft collided in the sky over Britain.

The above-mentioned facts are far from complete. The projected increase in the density of air traffic, changes in the dynamics of the relative motion of aircraft and the reduction of separation standards, obviously, will increase the likelihood of dangerous collision of aircraft and as a consequence - the emergence of conflict situations. In these conditions, the role of systems for detecting and preventing conflict situations is significantly increased.

The aim of this research is developing an approach to risk assessment problem of convergence trajectories of dynamic objects, which will be used in the development of a software product to improve safety and, as a consequence, the preservation of human lives.

In addition to the solving task, the global problem contains the following tasks:

- finding the coefficients of the stochastic system;

- solution of the system of stochastic differential equations.

The risk of convergence and conflict situation between aircrafts is calculated.

A conflict situation (CS) should be understood as the possibility of a collision, a dangerous convergence or crossing of the trajectories of two dynamic objects.

It is assumed that aircrafts are under the influence of different random perturbation vectors under different initial conditions.

\section{Materials and methods for risk assessment problem of convergence trajectories of dy- namic objects}

2. 1. Description of the research object

The object of research in this article is a pair of dynamic objects - aircrafts. Aircrafts, as dynamic objects, are characterized by a state vector.

Let's establish the components of the state vector for each aircraft that will be used for the numerical study:

$$
\begin{gathered}
D_{j}=\left\{x_{j}(t), y_{j}(t), z_{j}(t), t, \Delta x_{j}(t), \Delta y_{j}(t), \Delta z_{j}(t), v_{x j}(t), v_{y j}(t), v_{z j}(t),\right. \\
\left.v_{0 j}, \Delta v_{x j}(t), \Delta v_{y j}(t), \Delta v_{z j}(t), W_{j}(t)\right\}, \\
j=1,2,
\end{gathered}
$$

where $x_{j}(t)$ - the coordinate of the longitudinal position of the aircraft at time $t ; y_{j}(t)$ - coordinate of the lateral position of the aircraft at time $t ; z_{j}(t)$ - coordinate of the vertical position of the aircraft at time $\mathrm{t} ; \mathrm{t}$ - current time; $\Delta \mathrm{x}_{\mathrm{j}}(\mathrm{t})$ - deviation of the longitudinal position of the aircraft from the line of a given course; $\Delta \mathrm{y}_{\mathrm{j}}(\mathrm{t})$ - deviation from the line of a given course; $\Delta \mathrm{z}_{\mathrm{j}}(\mathrm{t})-$ deviation of the vertical position of the aircraft from the line of a given course; $v_{x j}(t)$ - speed of 
flight along the $\mathrm{x}$ axis; $\mathrm{v}_{\mathrm{yj}}(\mathrm{t})$ - speed of flight along the y axis; $\mathrm{v}_{\mathrm{zj}}(\mathrm{t})$ - speed of flight along the $\mathrm{z}$ axis; $\mathrm{v}_{0 \mathrm{j}}$ - the given speed of flight; $\Delta \mathrm{v}_{\mathrm{xj}}(\mathrm{t})$ - deviation from the given speed along the $\mathrm{x}$ axis; $\Delta \mathrm{v}_{\mathrm{yj}}(\mathrm{t})$ - deviation from the given speed along the y axis; $\Delta \mathrm{v}_{\mathrm{zj}}(\mathrm{t})$ - deviation from the given speed along the $\mathrm{z}$ axis; $\mathrm{W}_{\mathrm{j}}(\mathrm{t})$ - Wiener process, with the help of which the influence of the external environment on the aircraft is modeled.

These components of the state vector will be used to construct a stochastic motion model of the aircraft.

\section{2. Method for assessment of the convergence trajectories}

The state of an object at a certain time is described by a random vector process

$$
\mathrm{x}_{\mathrm{t}}=\left\{\mathrm{x}_{1}(\mathrm{t}), \ldots, \mathrm{x}_{\mathrm{N}}(\mathrm{t})\right\}
$$

in N-dimensional space. The components of a random vector $\mathrm{x}_{\mathrm{t}}$ are the coordinates and speeds of the dynamic object.

Let's write a multidimensional linear stochastic differential equation in the general form

$$
\mathrm{dx}_{\mathrm{t}}=\mathrm{a}\left(\mathrm{x}_{\mathrm{t}}, \mathrm{t}\right) \mathrm{dt}+\sum\left(\mathrm{x}_{\mathrm{t}}, \mathrm{t}\right) \mathrm{df} \mathrm{f}_{\mathrm{t}}, \mathrm{x}_{0}=\mathrm{x}(0, \omega)
$$

where $x_{t} \in \mathfrak{R}^{\mathrm{n}}$ - the random Markov process is a solution of equation (1) (according to Dub's theorem [11]); $\mathrm{f}_{\mathrm{t}} \in \mathfrak{R}^{\mathrm{m}}, \mathrm{F}_{\mathrm{t}}$ - measurable for all $\mathrm{t} \in[0, \mathrm{~T}]$ the standard Wiener process with independent components $\mathrm{f}_{\mathrm{t}}^{(\mathrm{i})} ; \mathrm{i}=1, \ldots, \mathrm{m} ; \mathrm{a}: \mathfrak{R}^{\mathrm{n}} \times[0, \mathrm{~T}] \rightarrow \mathfrak{R}^{\mathrm{n}}-$ drift coefficient; $\sum: \mathfrak{R}^{\mathrm{n}} \times[0, \mathrm{~T}] \rightarrow \mathfrak{R}^{\mathrm{n} \times \mathrm{m}}-$ diffusion coefficient; $\mathrm{x}_{0}-$ initial condition; $\mathrm{x}_{0}, \mathrm{f}_{\mathrm{t}}-\mathrm{f}_{0}, \mathrm{t}>0$ - stochastic independent processes [12].

Each element of the vector $\mathrm{D}_{\mathrm{j}}$ corresponds to an element of a multidimensional Markov process $\mathrm{x}_{\mathrm{t}}$, which in turn is described by the Ornstein-Uhlenbeck random process

$$
d x_{t}=-\mu\left(x_{t}-\alpha\right) d t+\sigma d W_{t}
$$

where

$$
\mu>0, \sigma>0, \mathrm{t} \in[0, \infty) .
$$

The motion of the air object will be described not in a spherical coordinate system, but in a rectangular coordinate system, which is due to the relatively small distance between the objects.

Let's consider a rectangular coordinate system in space, the Ox axis is directed along the line of the given path, the Oy axis is directed along the line of the aircraft's lateral position, the Oz axis is directed along the line of vertical position of the aircraft (Fig. 1), where $x(t)$ - coordinate of the longitudinal position of the aircraft at time $t ; y(t)$ - coordinate of the lateral position of the aircraft from the line of the given path; $\mathrm{v}_{\mathrm{x}}(\mathrm{t})$ - aircraft speed; $\Delta \mathrm{v}_{\mathrm{x}}(\mathrm{t})$ - deviation from the given speed along the $\mathrm{x}$ axis; $\Delta \mathrm{v}_{\mathrm{y}}(\mathrm{t})$ - deviation from the given speed along the y axis; $\Delta \mathrm{v}_{\mathrm{z}}(\mathrm{t})-$ deviation from the given speed along the $\mathrm{z}$ axis.

The process of deviation from the line of a given path is a random process, and it can be approximated by the Ornstein-Uhlenbeck random process:

$$
d y(t)=-\alpha_{y} y(t) d t+\sigma_{y} d W_{y}(t)
$$

where $\alpha_{\mathrm{y}}, \sigma_{\mathrm{y}}-$ known positive coefficients [12].

A random Markov process is a solution of the stochastic differential Ornstein-Uhlenbeck equation [13].

The deviation of the aircraft from a given flight speed for each coordinate is also described by the Ornstein-Uhlenbeck random process: 


$$
\mathrm{d} \Delta \mathrm{v}=-\alpha \Delta \mathrm{vdt}+\sigma \mathrm{dW}
$$

where $\alpha, \sigma-$ known positive coefficients; $\mathrm{W}=\mathrm{W}_{\mathrm{y}}(\mathrm{t})-$ standard Wiener process; $\Delta \mathrm{v}=\mathrm{v}(\mathrm{t})-$ deviation from the given speed.

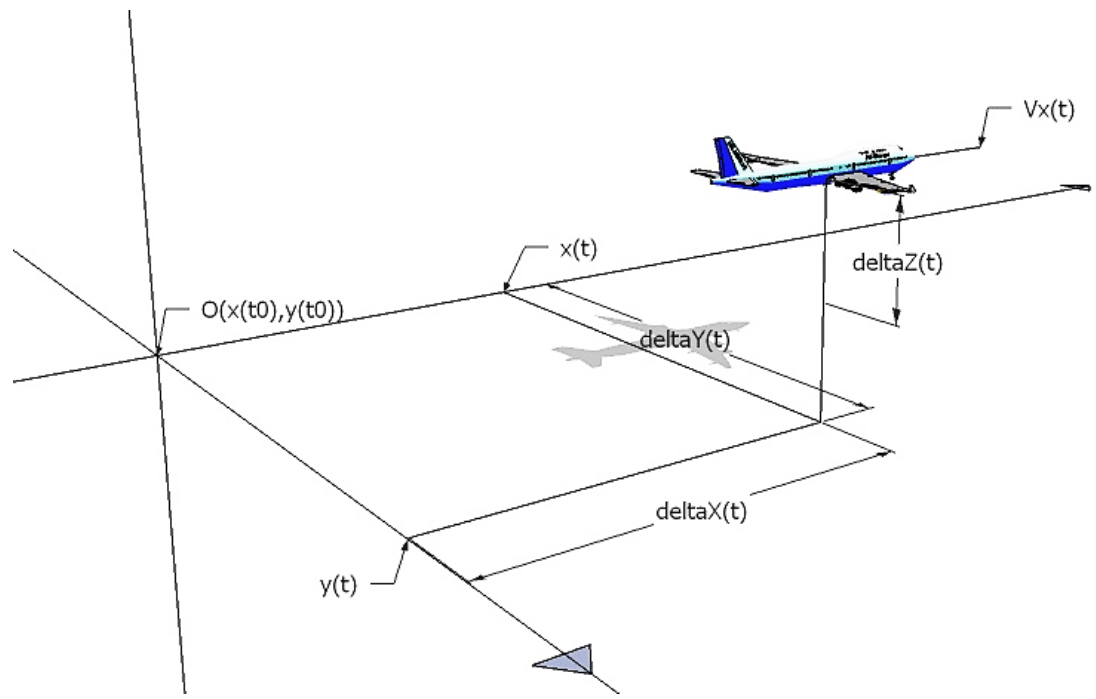

Fig. 1. Motion of the aircraft in the coordinate system

The process of deviation of the aircraft in longitudinal motion is most influenced by wind influences, so for the longitudinal coordinate let's write the model in the form

$$
\mathrm{dx}(\mathrm{t})=\left(\mathrm{v}_{0}+\Delta \mathrm{v}_{\mathrm{x}}(\mathrm{t})\right) \mathrm{dt}
$$

where $\mathrm{x}(\mathrm{t})$ - coordinate of the longitudinal position of the aircraft at time $\mathrm{t} ; \Delta \mathrm{v}_{\mathrm{x}}(\mathrm{t})=\mathrm{v}_{\mathrm{x}}(0)-\mathrm{v}_{0}-$ deviation from the given flight speed; $\mathrm{v}_{0}$ - given speed of flight of aircraft along the line of a given path.

Wind influences will be calculated based on data that is collected and processed in real time.

\section{Results for risk assessment problem of convergence trajectories}

Let's write a system of stochastic differential equations in which the control action and the perturbation along the $\mathrm{x}$ and $\mathrm{y}$ axes are taken into account. The coordinate $\mathrm{z}$ is not taken into account, because the change in the position of the object relative to the $\mathrm{z}$ axis is small, which allows one to make an assumption and not take this coordinate into account. The process of deviation from a given flight speed along the $\mathrm{x}$ and $\mathrm{y}$ axes is a random process and is described by the following for a multidimensional Markov process (state vector):

$$
x_{t}=\left\{x(t), y(t), \Delta v_{x}(t), \Delta v_{y}(t)\right\}
$$

On the basis of equations (3)-(5), let's write the system of stochastic differential equations [14]

$$
\left\{\begin{array}{l}
\mathrm{dx}(\mathrm{t})=\left(\mathrm{v}_{0}+\Delta \mathrm{v}_{\mathrm{x}}(\mathrm{t})\right) \mathrm{dt} \\
\mathrm{d} \Delta \mathrm{v}_{\mathrm{x}}=-\alpha_{\mathrm{x}} \Delta \mathrm{v}_{\mathrm{x}} \mathrm{dt}+\sigma_{\mathrm{x}} \mathrm{dW} \\
\mathrm{dy}(\mathrm{t})=\mathrm{v}_{\mathrm{y}}(\mathrm{t}) \mathrm{dt} \\
\mathrm{d} \Delta \mathrm{v}_{\mathrm{y}}=-\alpha_{\mathrm{y}} \Delta \mathrm{v}_{\mathrm{y}} \mathrm{dt}+\sigma_{\mathrm{y}} \mathrm{dW}
\end{array}\right.
$$

or in the vector form: 


$$
\mathrm{dx}_{\mathrm{t}}=\left[\begin{array}{c}
\mathrm{v}_{0}+\Delta \mathrm{v}_{\mathrm{x}}(\mathrm{t}) \\
\mathrm{v}_{\mathrm{y}} \\
-\alpha_{\mathrm{x}} \Delta \mathrm{v}_{\mathrm{x}} \\
-\alpha_{\mathrm{y}} \Delta \mathrm{v}_{\mathrm{y}}
\end{array}\right] \mathrm{dt}+\left[\begin{array}{c}
0 \\
0 \\
\sigma_{\mathrm{x}} \mathrm{W}_{\mathrm{x}}(\mathrm{t}) \\
\sigma_{\mathrm{y}} \mathrm{W}_{\mathrm{y}}(\mathrm{t})
\end{array}\right], \mathrm{x}_{0}=\left[\begin{array}{l}
0 \\
0 \\
\mathrm{v}_{\mathrm{x}}(0) \\
\mathrm{v}_{\mathrm{y}}(0)
\end{array}\right]
$$

or

$$
\mathrm{dx}_{\mathrm{t}}=\left[\mathrm{v}_{0} \mathrm{e}+\Lambda\left[\begin{array}{c}
\mathrm{v}_{\mathrm{x}} \\
\mathrm{v}_{\mathrm{y}}
\end{array}\right]\right] \mathrm{dt}+\mathrm{SdW},
$$

where

$$
\mathrm{e}=[1,0,0,0]^{\mathrm{T}} ; \Lambda=\left[\begin{array}{cr}
1 & 0 \\
0 & 1 \\
-\alpha_{\mathrm{x}} & 0 \\
0 & -\alpha_{\mathrm{y}}
\end{array}\right] ; \mathrm{W}(\mathrm{t})=\left[\begin{array}{l}
\mathrm{W}_{\mathrm{x}}(\mathrm{t}) \\
\mathrm{W}_{\mathrm{y}}(\mathrm{t})
\end{array}\right] ; \mathrm{S}=\left[\begin{array}{cc}
0 & 0 \\
0 & 0 \\
\sigma_{\mathrm{x}} & 0 \\
0 & \sigma_{\mathrm{y}}
\end{array}\right] \text {. }
$$

Let's suppose that aircrafts move at one altitude level in one direction, parallel to each other. Let's solve the system (7) with the following initial data: the coefficients for the deviation model from the line of the given path are taken

$$
\Lambda_{1}=\left[\begin{array}{cc}
1 & 0 \\
0 & 1 \\
-0.1 & 0 \\
0 & -0.1
\end{array}\right]
$$

for the first aircraft and

$$
\Lambda_{2}=\left[\begin{array}{cc}
1 & 0 \\
0 & 1 \\
-0.2 & 0 \\
0 & -0.2
\end{array}\right]
$$

for the second aircraft, with the initial conditions

$$
\mathrm{x}(0)=0 \mathrm{y}(0)=0,6, \Delta \mathrm{v}_{\mathrm{x}}(\mathrm{t})=0, \Delta \mathrm{v}_{\mathrm{y}}(\mathrm{t})=0
$$

for the first aircraft and

$$
\mathrm{x}(0)=0, \mathrm{y}(0)=10, \Delta \mathrm{v}_{\mathrm{x}}(\mathrm{t})=0, \Delta \mathrm{v}_{\mathrm{y}}(\mathrm{t})=0
$$

for the second aircraft. All values are measured in conventional units.

The projection of the relative lateral coordinates of two air objects is shown in Fig. 2.

The projections of the relative vertical coordinates of the two aircrafts $y_{1,2}(t)$ are shown in Fig. 3.

The evolution of the phase trajectories of system (7) on the time interval $t \in\left[t_{1}, t_{2}\right]$, $\mathrm{t}_{1}=0, \mathrm{t}_{2}=20$ is shown in Fig. $\mathbf{4 , 5}$.

The relative trajectories of the aircraft motion in space are shown in Fig. 5. 


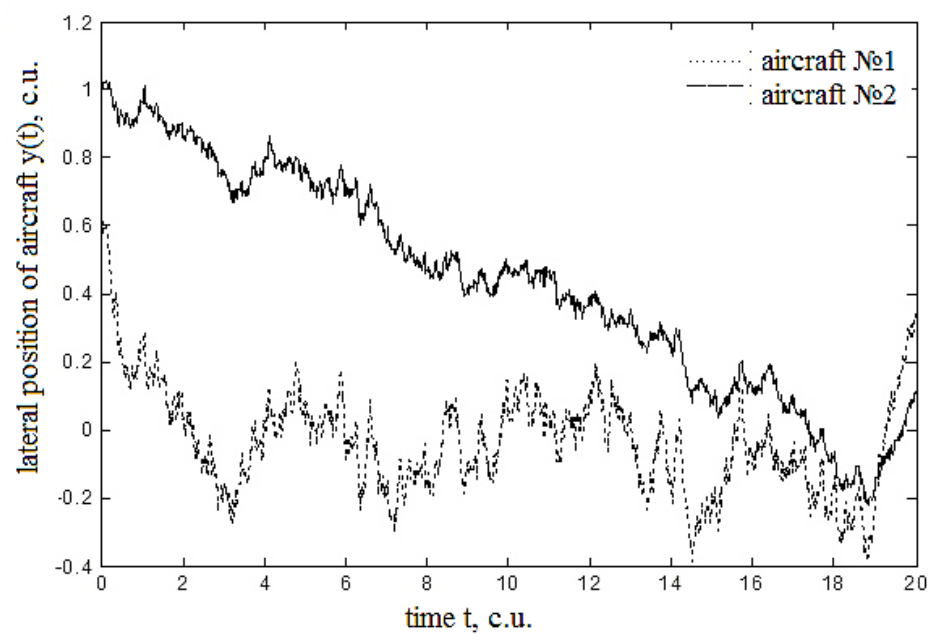

Fig. 2. Realization of projections of relative lateral coordinates of two aircrafts $y_{1,2}(t)$ lateral position of aircraft $y(t)$, c.u.

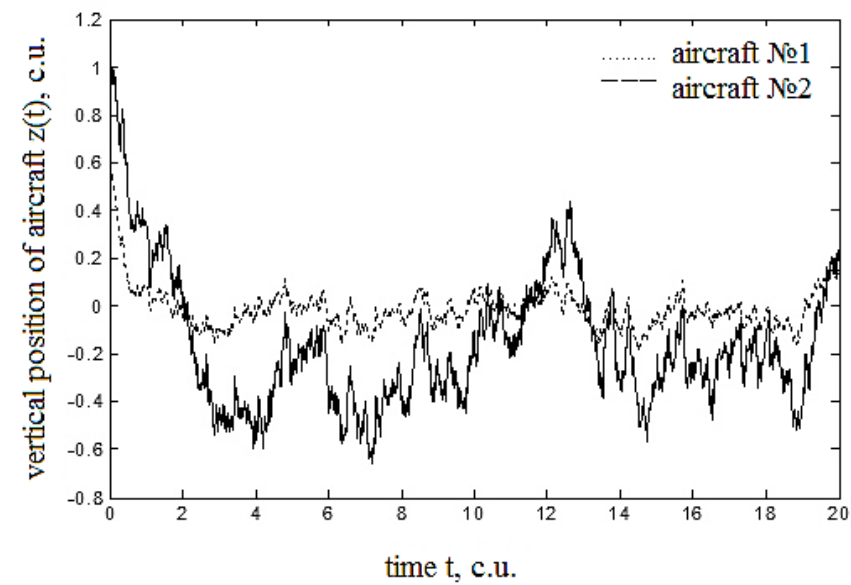

Fig. 3. Projections of the relative vertical coordinates of two aircrafts, Markov processes $\mathrm{z}_{1,2}(\mathrm{t})$

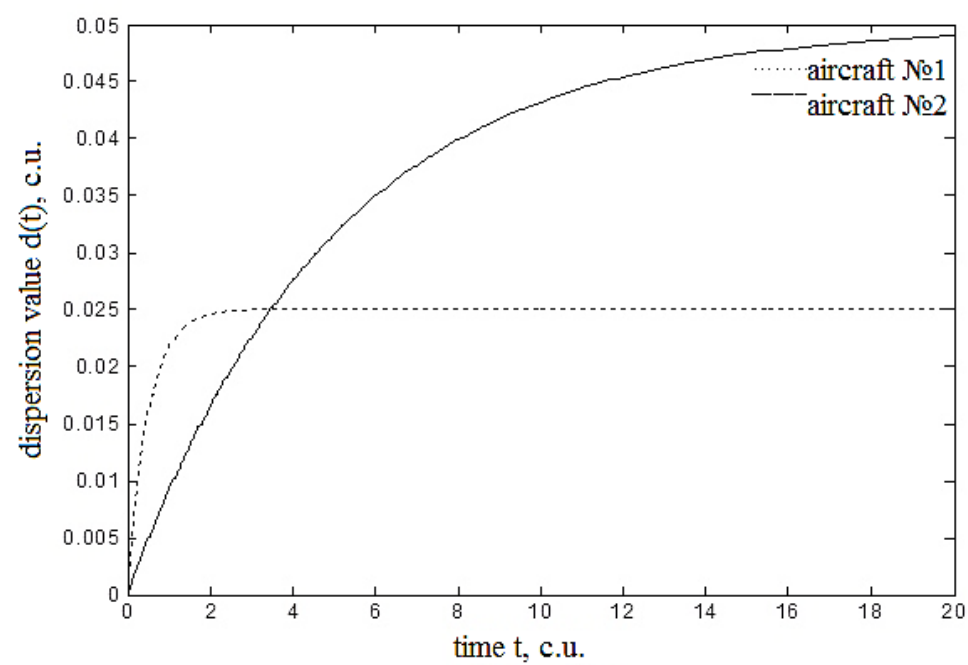

Fig. 4. Graphs of dispersion of lateral aircraft deviation 


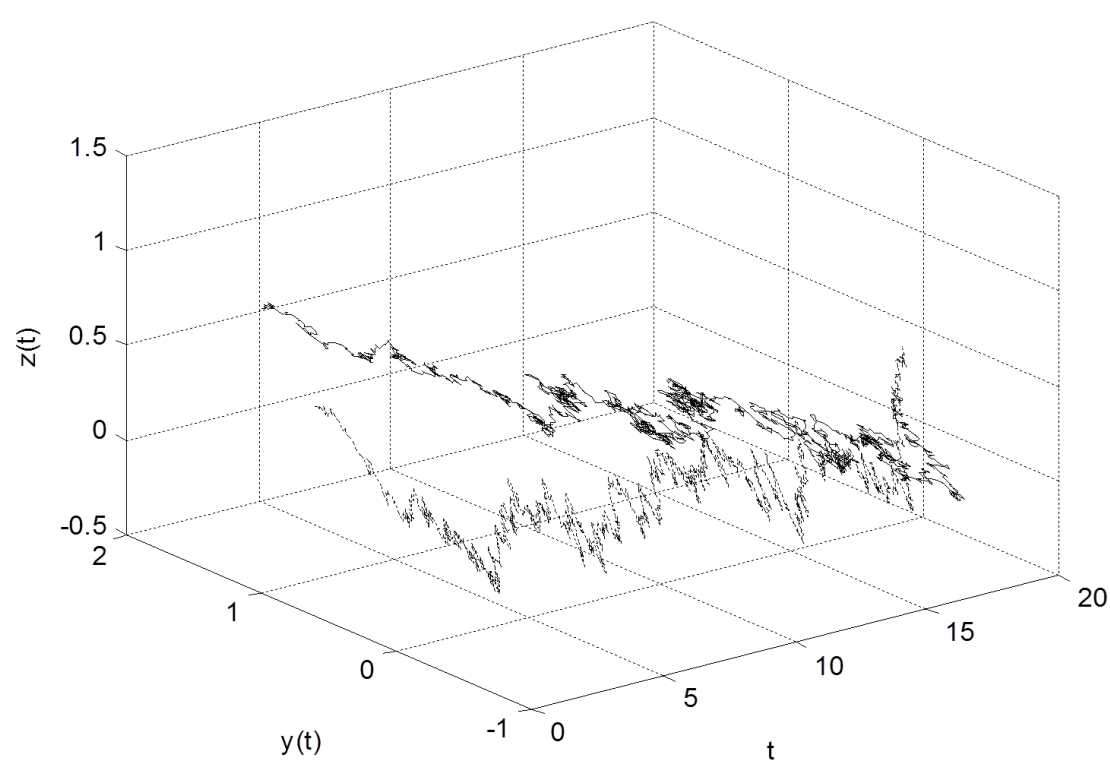

Fig. 5. The relative trajectories of the aircraft motion in space

\section{Discussion of research results}

Fig. 2 shows the relative trajectories of the motion of two aircraft, which are projections of displacements in the space of lateral coordinates of the aircraft in the plane under the action of random perturbations. To construct the graph of the realization of a random Markov process $\mathrm{y}_{1,2}(\mathrm{t})$, a system (9) is solved with initial conditions $\mathrm{x}(0)=0, \mathrm{y}(0)=0,6, \Delta \mathrm{v}_{\mathrm{x}}(\mathrm{t})=0, \Delta \mathrm{v}_{\mathrm{y}}(\mathrm{t})=0$ for the first aircraft and $\mathrm{x}(0)=0, \mathrm{y}(0)=1, \Delta \mathrm{v}_{\mathrm{x}}(\mathrm{t})=0, \Delta \mathrm{v}_{\mathrm{y}}(\mathrm{t})=0$ for the second aircraft.

Fig. 3 shows the relative trajectories of the motion of two aircrafts, which are projections of displacements in the space of longitudinal coordinates of the aircraft in the plane under the action of random perturbations. To construct the graph of the realization of a random Markov $\operatorname{processx}_{1,2}(\mathrm{t})$, a system (7) is solved with the initial conditions $\mathrm{x}(0)=0,6, \mathrm{y}(0)=0, \Delta \mathrm{v}_{\mathrm{x}}(\mathrm{t})=0, \Delta \mathrm{v}_{\mathrm{y}}(\mathrm{t})=0$ for the first aircraft and $\mathrm{x}(0)=1, \mathrm{y}(0)=0, \Delta \mathrm{v}_{\mathrm{x}}(\mathrm{t})=0, \Delta \mathrm{v}_{\mathrm{y}}(\mathrm{t})=0$ for the second aircraft.

Fig. 4 shows graphs of the dispersions of the random functions $y_{1,2}(t)$ of each aircraft, characterizing the magnitude of the deviation from the given trajectories of aircraft motion.

Fig. 5 shows the graphs of the dispersions of aircraft motion in three-dimensional space. Where the time interval $\mathrm{t} \in\left[\mathrm{t}_{1}, \mathrm{t}_{2}\right], \mathrm{t}_{1}=0, \mathrm{t}_{2}=20$ is plotted on the $\mathrm{x}$ axis, and, on the $\mathrm{y}$ axis - the change in the lateral position trajectory -the values of the Markov process $y(t)$. On the $z$ axis - the change in the trajectory in the vertical coordinate position -the value of the Markov process $x(t)$.

When considering this option, when both aircrafts are moving on the same air level in the same direction, we will be interested in the projection of the lateral position of the aircraft, since the projections of the longitudinal coordinates, in this case, can intersect as many times as desired.

Based on the above graphs of relative motion trajectories, a conflict situation appears on the time interval $\mathrm{t} \in[0,20]$. Table 1 shows the distance between two aircrafts in space at time $\mathrm{t}$.

Table 1

Table of distances between aircrafts at time $t$

Time, $t$

\begin{tabular}{ccccccccccc}
\hline Characteristics & 18,03 & 18,04 & 18,05 & 18,06 & 18,07 & 18,08 & 18,09 & 18,1 & 18,11 \\
& & & & & & & & & \\
Distance, c. u. & 0.110 & 0.093 & 0.107 & 0.072 & 0.131 & 0.165 & 0.170 & 0.180 & 0.217
\end{tabular}


The origin of CS occurs when the allowed distance between random processes $\mathrm{x}_{\mathrm{t}}$ will satisfy the inequality $\mathrm{d}<1$, where $\mathrm{d}$ - the distance between two aircrafts at time $\mathrm{t}$. Based on the results of this calculation, with the given initial conditions, the results of the CS evaluation are obtained. Proceeding from them, the occurrence of CS at the time $t=18,06 \mathrm{c}$. $\mathrm{u}$. is forecasted. Part of the calculations is shown in Table $\mathbf{1 .}$

From Fig. 5 it can be concluded that dispersion of the lateral deviation from the trajectory of the motion of the second aircraft increases in time. Dispersion of the lateral deviation of the first aircraft remains constant and equal to $\mathrm{D}=0,025$ throughout the entire time interval. Thus, motion of the second aircraft is extremely dangerous from the point of view of the emergence of a conflict situation.

\section{Conclusions}

A mathematical model of the motion of an aircraft is developed in the article, taking into account the influence of random perturbations, based on the mathematical apparatus of linear stochastic differential equations. A numerical example of the problem of assessing the convergence trajectory of two dynamic objects is solved. The problem is solved on a test example with given initial conditions. Based on the numerical values obtained after modeling in the MatLab, an assessment of the conflict situation is obtained. Further development of the article consists in finding the probability of a conflict situation from the multidimensional Fokker-Planck-Kolmogorov equation.

\section{References}

[1] Dowek, G., Munoz, C., Geser, A. (2001). Tactical Conflict Detection and Resolution in a 3-D Airspace. Europe Air Traffic Management R\&D Seminar Santa Fe, 4 (2), 242-249.

[2] Zolotuhin, V. V., Isaev, V. K., Davidson, B. H. (2009). Aktual'nye zadachi upravlenija vozdushnym dvizheniem. Trudy MFTI, 1 (3), 94-114.

[3] Alonso-Ayuso, A., Escudero, L. F., Martín-Campo, F. J., Mladenović, N. (2014). A VNS metaheuristic for solving the aircraft conflict detection and resolution problem by performing turn changes. Journal of Global Optimization, 63 (3), 583-596. doi: 10.1007/s10898-014-0144-8

[4] Durand, N., Alliot, J. (2009) Ant colony optimization for air traffic conflict resolution. Eighth USA/Europe air traffic management research and development seminar (ATM2009), 7.

[5] Goloskokov, A. E., Brodskij, M. A. (2011). Modelirovanie sovmestnogo dvizhenija dinamicheskih obektov s uchetom vlijanija sluchajnyh vozmushhenij. Vestnik NTU «HPI», 9, 73-80.

[6] 10 Samyh Uzhasnyh Aviakatastrof V Istorii Chelovechestva. Available at: http:/tvoipolet. ru/10-samyx-strashnyx-aviakatastrof/?history=0\&amp;sample=21\&amp;ref=1

[7] 10 Samyh uzhasnyh aviakatastrof v istorii chelovechestva. Available at: http://necro-tv.livejournal.com/6910.html???history=0\&amp;sample=21\&amp;ref=0

[8] Stolknovenija i ugroza stolknovenij samoletov v 2000-2009 gg. Spravka. Available at: https:// ria.ru/incidents/20090514/171046868.html???history=0\&amp;sample=29\&amp;ref=0

[9] Aviakatastrofa v Tenerife - 1977. Available at: годhttp://aircraft.jofo.me/640136.html???history=0\&amp;sample=21\&amp;ref $=2$

[10] V Velikobritanii stolknulis' dva samoleta. Available at: https://enta.ru/news/2008/08/17/collision/???history=0\&amp;sample=35\&amp;ref $=1$

[11] Dub, Dzh. L. (1956). Verojatnostnye processy. Ripol Klassik, 605.

[12] Kuznecov, D. F. (2008). Stohasticheskie differencial'nye uravnenija: teorija i praktika. Differencial'nye uravnenija i processy upravlenija, 29.

[13] Tihonov, V. I., Mironov, M. A. (1977). Markovskie processy. Moscow: Sovetskoe radio, 488.

[14] Sveshnikov, A. A. (1968). Prikladnye metody teorii sluchajnyh funkcij. Moscow: Nauka, 449. 